CLINICAL STUDY

\title{
High-mobility group protein B 1: a new biomarker of metabolic syndrome in obese children
}

\author{
Teresa Arrigo $^{1}$, Valeria Chirico ${ }^{1}$, Vincenzo Salpietro ${ }^{1}$, Caterina Munafò ${ }^{1}$, Valeria Ferraù ${ }^{1}$, Eloisa Gitto ${ }^{2}$, \\ Antonio Lacquaniti ${ }^{3}$ and Carmelo Salpietro ${ }^{1}$ \\ ${ }^{1}$ Department of Pediatric Sciences, ${ }^{2}$ Neonatal Intensive Care Unit, Institute of Medical Pediatrics and ${ }^{3}$ Department of Internal Medicine, University of \\ Messina, 98100 Messina, Italy
}

(Correspondence should be addressed to C Salpietro; Email: carmelo.salpietro@unime.it)

\begin{abstract}
Introduction: Obesity is associated with a chronic low-grade inflammation. High-mobility group box 1 protein (HMGB1) plays a key role in inflammation and immunostimulatory and chemotactic processes. The aim of the study was to assess the role of HMGB1 in obese children and to evaluate its diagnostic profile in identifying childhood obesity-related complications, such as the metabolic syndrome (MS).

Patients and methods: Sixty obese children were enrolled and compared with 40 healthy children (control). Homeostasis model assessment of insulin resistance (HOMA-IR), lipid profile, thyroid hormones, and pro- and anti-inflammatory peptides such as C-reactive protein (CRP), adiponectin, interleukin 6 (IL6), IL18, IL23, TNF $\alpha$, resistin, and HMGB1 were evaluated. Receiver operating characteristics (ROC) analysis was employed to calculate the area under the curve (AUC) for HMGB1, IL6, and adiponectin to find the best cutoff values capable of identifying MS in obese children. Results: HMGB1 levels were statistically higher in obese patients than in the control group $(19.4 \pm 6.8$ vs $3.7 \pm 1.2 \mathrm{ng} / \mathrm{ml} ; P<0.0001)$. In obese patients, IL18, IL6, and resistin levels were significantly high, while adiponectin levels were low. At multivariate analysis, HMGB1 was found to be independently correlated with BMI, IL23, IL6, free triiodothyronine, HDL, and HOMA-IR. At ROC analysis, HMGB1 showed higher sensitivity and specificity (AUC, 0. 992; sensitivity, 94.7\%; specificity, 97.5\%) than IL6 and adiponectin in identifying MS in obese children.

Conclusion: HMGB1 plays an important role in the inflammatory process associated with childhood obesity. This peptide may be an important diagnostic marker for obesity-related complications, such as MS.
\end{abstract}

European Journal of Endocrinology 168 631-638

\section{Introduction}

Childhood obesity is an important risk factor for atherosclerosis and metabolic syndrome (MS), whose features include insulin resistance, dyslipidemia, and hypertension (1). Furthermore, the MS prevalence increases with the severity of obesity and reaches $50 \%$ in severely obese children (2). Increasing evidence suggests that numerous endocrine peptides, interleukins (IL), and cytokines, which are secreted mostly from adipose tissue, play a role in both short- and longterm energy balance, metabolism, and inflammatory response (3). A recent study indicates that inflammatory mechanisms linking obesity to its metabolic and cardiovascular complications are already activated in childhood obesity (4). Adiponectin, a $30 \mathrm{kDa}$ protein highly expressed in adipose tissue, is decreased in obese patients, and it is characterized by insulin-sensitizing, anti-inflammatory, and anti-atherogenic properties (5). $\mathrm{TNF} \alpha$, a proinflammatory cytokine mainly produced by macrophages and lymphocytes, is involved in insulin resistance and endothelial inflammatory processes (6).

IL6, significantly enhanced by adipose tissue in obesity, is a circulating multifunctional cytokine with various functions such as inflammation, host defense, and tissue injury. The two major adverse effects of increased IL6 in obesity are insulin resistance and increased risk for cardiovascular complications (7). Resistin is another adipokine that may play a role in the development of obesity-related insulin resistance (8). In adults, it is known that obesity is associated with a chronic low-grade inflammation and inflammatory pathways could be critical in the mechanisms underlying obesity-related metabolic diseases (9).

Chronic low-grade systemic inflammation can be evaluated by circulating C-reactive protein (CRP), a nonspecific acute-phase reactant synthesized in liver, which may also have direct pro-inflammatory actions (10). Apart from adipocytes, other cells located in adipose tissue such as endothelial cells, fibroblasts, and 
immune cells may secrete inflammatory peptides and chemokines. In particular, high-mobility group box 1 protein (HMGB1), a $30 \mathrm{kDa}$ nuclear and cytosolic ubiquitous protein, is actively secreted by innate immune cells and it has been shown to stimulate necrosis-induced inflammation (11). Moreover, HMGB1 induces other cytokines such as TNF $\alpha$, IL1, IL6, and IL8 (12). HMGB1 has been shown to interact with toll-like receptor 2 (TLR2), TLR4, and the receptor for advanced glycation end products, inducing immunostimulatory and chemotactic responses (13). Elevated HMGB1 levels in serum have been found in acute inflammatory conditions, but there is no evidence about its role in childhood obesity (14).

The aim of this study was to identify the chronic low-grade inflammatory process, characterizing obese children, using a panel of biomarkers. Moreover, we evaluated the role of HMGB1 in obesity and its relationship with inflammatory cytokines such as IL6, IL18, IL23, TNF $\alpha$, adiponectin, and resistin. Furthermore, the diagnostic role of HMGB1 for MS was also assessed.

\section{Materials and methods}

\section{Patient and control groups}

A total of 100 children were enrolled in the study. In particular, 60 children or adolescents (mean age $11.1 \pm 2.9$ years, 33 females) who had been referred to the Section of Nutrition and Dietetics, Genetics and Pediatric Immunology Unit, Department of Pediatrics, University of Messina, between November 2011 and April 2012 were enrolled in the obese group. Subjects were eligible if they were healthy, were between 8 and 18 years of age, and had a BMI that exceeded the age- and genderInternational Obesity Task Force (IOTF) BMI cutoff points for children ( $>2$ s.D. for gender and age) (15).

Exclusion criteria included: hepatic, infectious, or endocrine diseases (other than diabetes or impaired glucose tolerance (IGT)); syndromic obesity; craniopharyngioma; and the use of medication that alters blood pressure or glucose or lipid metabolism. All subjects were Caucasian.

Forty healthy children (mean age $10.3 \pm 1.6$ years; 20 females) were enrolled as controls (control group). Subjects had to be normal weight. Apart from obesity, inclusion/exclusion criteria were identical to those used for the obese group.

The study protocol was approved by the Hospital's Ethics Committee. Written informed consent was obtained from the parents and informed assent from the children and adolescents.

\section{Procedures}

Subjects were evaluated at $0800 \mathrm{~h}$, after an overnight fast. A detailed medical and familial history was obtained for all subjects, and a physical examination was performed, including staging of puberty according to the criteria of Tanner \& Whitehouse (16).

Waist circumference (WC) was measured midway between the lowest rib and the iliac crest at the end of gentle expiration. It was calculated according to the standards assessed by McCarthy et al. (17).

Blood pressure was measured three times with an appropriate size cuff while the subjects were seated and the lowest measurement was used for analysis (18). All measurements were made by the same pediatrician.

\section{Definitions}

The relative BMI of each patient was calculated as the BMI divided by the BMI at 50th percentile for age and gender $\times 100$ (19). Subjects were classified as hypertensive if their systolic and/or diastolic blood pressure exceeded the 90th percentile for age and sex after adjustment for height (18). The degree of hypertension was evaluated by the difference between the systolic or diastolic blood pressure measured in one subject and the 90th percentile for age and sex after adjustment for height.

Abdominal obesity was defined using the sex- and age-specific 90th WC percentile as described by McCarthy et al. (17).

Biochemical hyperinsulinism was defined as fasting levels of insulin $>15 \mathrm{mU} / \mathrm{ml}$, according to Ten \& Maclaren (20).

Insulin resistance was determined by the homeostatic model assessment (HOMA) and calculated according to the following formula: (insulin $(\mu \mathrm{U} / \mathrm{ml}) \times$ serum glucose $(\mathrm{mmol} / \mathrm{l})) / 22.5(21)$. The HOMA index was validated as a reliable measure of insulin sensitivity in obese and nonobese children and adolescents $(22,23)$. Impaired insulin sensitivity was defined as a HOMA of insulin resistance (HOMA-IR) of 2.5 or higher in prepubescent patients (24).

Obese children and adolescents were classified as having the MS if they met three or more of the following criteria for age and sex: a BMI above the 97th percentile; systolic or diastolic blood pressure above the 95th percentile; a triglyceride (TG) level above the 95th percentile; a HDL-cholesterol level below the 5th percentile; and IGT (25).

\section{Collection of blood}

Baseline blood samples were obtained by venipuncture (cubital vein approach with butterfly) for measurements of levels of glucose, lipid profile, insulin, thyroid hormones, and pro- and anti-inflammatory peptides (CRP, adiponectin, IL6, IL18, IL23, TNF $\alpha$, resistin, and HMGB1). Serum (after allowing blood to clot at room temperature) or plasma (potassium EDTA) was rapidly obtained by refrigerated $\left(4^{\circ} \mathrm{C}\right)$ centrifugation at $2000 \boldsymbol{g}$ for $15 \mathrm{~min}$. Glucose, insulin, and lipids were 
immediately measured; aliquots for other assays were stored at $-20{ }^{\circ} \mathrm{C}$ until analysis.

\section{Biochemical analysis}

Adiponectin (R\&D Systems Europe, Wiesbaden, Germany), resistin (Linco Research, Inc., Minneapolis MN, USA), HMGB1 (IBL Shino Test Corporation, Hamburg, Germany), IL18 (Bender MedSystems GmbH, Vienna, Austria), IL23 (Biovendor, Space import-export SRL, Milan, Italy), IL6, and TNF $\alpha$ (DRG International, Inc., Mountainside, NJ, USA) levels were determined by ELISA, according to the manufacturer's instructions. The hs-CRP was measured by immunonephelometry (Dade-Behring, Marburg, Germany). Fasting plasma glucose was measured using a glucose oxidase method. Plasma insulin was measured by RIA (Diagnostic Product Corporation, Los Angeles, CA, USA).

Plasma total cholesterol, HDL-cholesterol, and TGs were determined by automated enzymatic methods (Boehringer Mannheim-Diagnostica). LDL-cholesterol concentrations were calculated using Friedewald's equation, considering that serum TG values remained below $4 \mathrm{mmol} / \mathrm{l}$ in every child. Thyroid function was determined by chemiluminescence (Architect system insulin/free thyroxine $\left(\mathrm{FT}_{4}\right)$ /free triiodothyronine $\left(\mathrm{FT}_{3}\right) / \mathrm{TSH}$; Abbott Diagnostics Division).

\section{Statistical analyses}

Statistical analyses were performed using Medcalc 8.0 for Windows package and GraphPad Prism 5.0 (GraphPad Software, Inc., San Diego, CA, USA). Data were presented as mean \pm s.D. for normally distributed values (at Kolmogorov-Smirnov test) and median (IQ range) for non-normally distributed values. Differences between groups were established by ANOVA followed by Bonferroni's test for normally distributed values and by Kruskal-Wallis analysis followed by Dunn's test for nonparametric values. Dichotomized values were compared using the $\chi^{2}$ test. The coefficient of Pearson's correlation was used to assess the correlations between variables. Multiple regression analysis with stepwise method was performed. Receiver operating characteristics (ROC) analysis was employed to calculate the area under the curve (AUC) for HMGB1, IL6, and adiponectin to find the best cutoff values capable of identifying MS in obese children. $P<0.05$ was considered to be statistically significant.

\section{Results}

\section{Characteristics of the population}

The main auxological, metabolic, and biochemical data of the patients are summarized in Table 1. The study group included 33 females and 27 males with a mean chronological age (CA) of $11.1 \pm 2.9$ years (range 7.5-14.5 years); the control group (20 females and 20 males) was well matched for CA $(10.3 \pm 1.6$ years; range 7.8-13.5 years). The mean BMI of obese subjects was $28.7 \pm 4.3 \mathrm{~kg} / \mathrm{m}^{2}$ (range $24.3-32.5 \mathrm{~kg} / \mathrm{m}^{2}$ ) and BMI SDS 2.7 \pm 0.3 (range 2.4-3.7). On the basis of the threshold BMI $z$-score, 23 (38\%) of the 60 obese patients were moderately obese and 11 (18\%) severely obese.

All obese patients presented abdominal obesity. $\mathrm{WC}$ was $76.8 \pm 10 \mathrm{~cm}$ (range $58.0-93 \mathrm{~cm}$ ), above 90th percentile, and was significantly $(P<0.05)$ different compared with the control values $(55.6 \pm$ $1.8 \mathrm{~cm}$; range $51.2-58.7 \mathrm{~cm})$. All patients were characterized by normal fasting glucose (FG) levels. In particular, FG range was 3.8-5.7 mmol/l, whereas FG levels were $4.73 \pm 0.4 \mathrm{mmol} / \mathrm{l}$. Fasting plasma insulin levels were $2.0(2.0-6.0) \mu \mathrm{U} / \mathrm{ml}$ (range 2.0$21.4 \mu \mathrm{U} / \mathrm{ml})$ and significantly higher $(P<0.001)$ than controls (3.0 (2.0-4.0) $\mu \mathrm{U} / \mathrm{ml}$; range $1.5-5.8 \mu \mathrm{U} / \mathrm{ml})$. Nine of 60 patients showed fasting hyperinsulinism (15\%) without clinical signs (i.e. acanthosis, skin tags). HOMA-IR was $1.5 \pm 1.6$ (range 0.3-3.7). Sixteen patients had impaired insulin sensitivity HOMA-IR (26\%). An impaired lipid profile was also assessed in obese children, with high levels of total cholesterol, LDL-cholesterol, and TGs, whereas HDL-cholesterol values were lower than the control group $(45.4 \pm 8.4$ vs $50.3 \pm 10.7 \mathrm{mg} / \mathrm{dl} ; P=0.005)$. Nineteen children (31\%) met the diagnostic criteria for MS.

\section{Cytokine levels in obese and control groups}

HMGB1 levels were statistically higher in obese patients than in the control group $(19.4 \pm 6.8$ vs

Table 1 Baseline demographic, clinical, and laboratory data of the study population.

\begin{tabular}{|c|c|c|c|}
\hline Parameter & $\begin{array}{l}\text { OB patients } \\
\quad(n=60)\end{array}$ & HS $(n=40)$ & $P$ value \\
\hline Gender (M/F) & 27/33 & $20 / 20$ & 0.62 \\
\hline Age (years) & $11.1 \pm 2.9$ & $10.3 \pm 1.6$ & 0.10 \\
\hline BMI $\left(\mathrm{kg} / \mathrm{m}^{2}\right)$ & $28.7 \pm 4.3$ & $18.4 \pm 1.5$ & 0.0006 \\
\hline BMI (SDS) & $2.7 \pm 0.3$ & $0.2 \pm 0.9$ & $<0.0001$ \\
\hline Systolic pressure $(\mathrm{mmHg})$ & $99.6 \pm 9.2$ & $98.4 \pm 6.3$ & 0.28 \\
\hline Diastolic pressure (mmHg) & $64.8 \pm 6.7$ & $61.4 \pm 4.3$ & 0.01 \\
\hline Serum glucose $(\mathrm{mmol} / \mathrm{l})$ & $4.7 \pm 0.4$ & $3.7 \pm 0.5$ & 0.22 \\
\hline Insulin $(\mu \mathrm{U} / \mathrm{ml})$ & $2.0(2.0-6.0)$ & $3.0(2.0-4.0)$ & $<0.0001$ \\
\hline HOMA-IR (\%) & $1.51 \pm 1.6$ & $0.7 \pm 0.5$ & 0.003 \\
\hline $\mathrm{WC}(\mathrm{cm})$ & $76.8 \pm 10$ & $55.6 \pm 1.8$ & $<0.0001$ \\
\hline $\mathrm{CRP}(\mathrm{mg} / \mathrm{l})$ & $0.3 \pm 0.27$ & $0.2 \pm 0.1$ & 0.10 \\
\hline $\mathrm{TNF} \alpha(\mathrm{pg} / \mathrm{ml})$ & $41.3 \pm 13.2$ & $23.5 \pm 4.7$ & $<0.0001$ \\
\hline IL18 (pg/ml) & $369.7 \pm 142$ & $236.6 \pm 66.4$ & $<0.0001$ \\
\hline IL23 (pg/ml) & $38.6 \pm 11.1$ & $36.9 \pm 10.3$ & 0.39 \\
\hline IL6 (pg/ml) & $36.5 \pm 6.4$ & $15.7 \pm 2.9$ & $<0.0001$ \\
\hline Adiponectin (ng/ml) & $11.5 \pm 2.2$ & $17.9 \pm 3.1$ & $<0.0001$ \\
\hline Resistin (ng/ml) & $8.3 \pm 1.2$ & $2.9 \pm 0.6$ & $<0.0001$ \\
\hline HMGB1 (ng/ml) & $19.4 \pm 6.8$ & $3.7 \pm 1.2$ & $<0.0001$ \\
\hline
\end{tabular}

$\mathrm{OB}$, obese; HS, healthy subjects; HMGB1, high-mobility group protein B1; HOMA, homeostasis model assessment; IL, interleukin; CRP, C-reactive protein; TNF, tumor necrosis factor; WC, waist circumference. 
$3.7 \pm 1.2 \mathrm{ng} / \mathrm{ml} ; \quad P<0.0001)$. TNF $\alpha$ levels were 41.3 $\pm 13.2 \mathrm{pg} / \mathrm{ml}$ in the obese group and they were significantly $(P<0.001)$ higher than the control group $(23.5$ $\pm 4.7 \mathrm{pg} / \mathrm{ml}$ ). IL18 levels were significantly higher compared with those measured in the controls (368.3 \pm 142 vs $236.6 \pm 66.4 \mathrm{pg} / \mathrm{ml} ; P<0.0001)$, as well as IL6 $\quad(36.5 \pm 6.4$ vs $\quad 15.7 \pm 2.9 \mathrm{pg} / \mathrm{ml} ; \quad P<0.0001)$ and resistin levels ( $8.3 \pm 1.2$ vs $2.9 \pm 0.6 \mathrm{ng} / \mathrm{ml} ; P<0.0001)$.
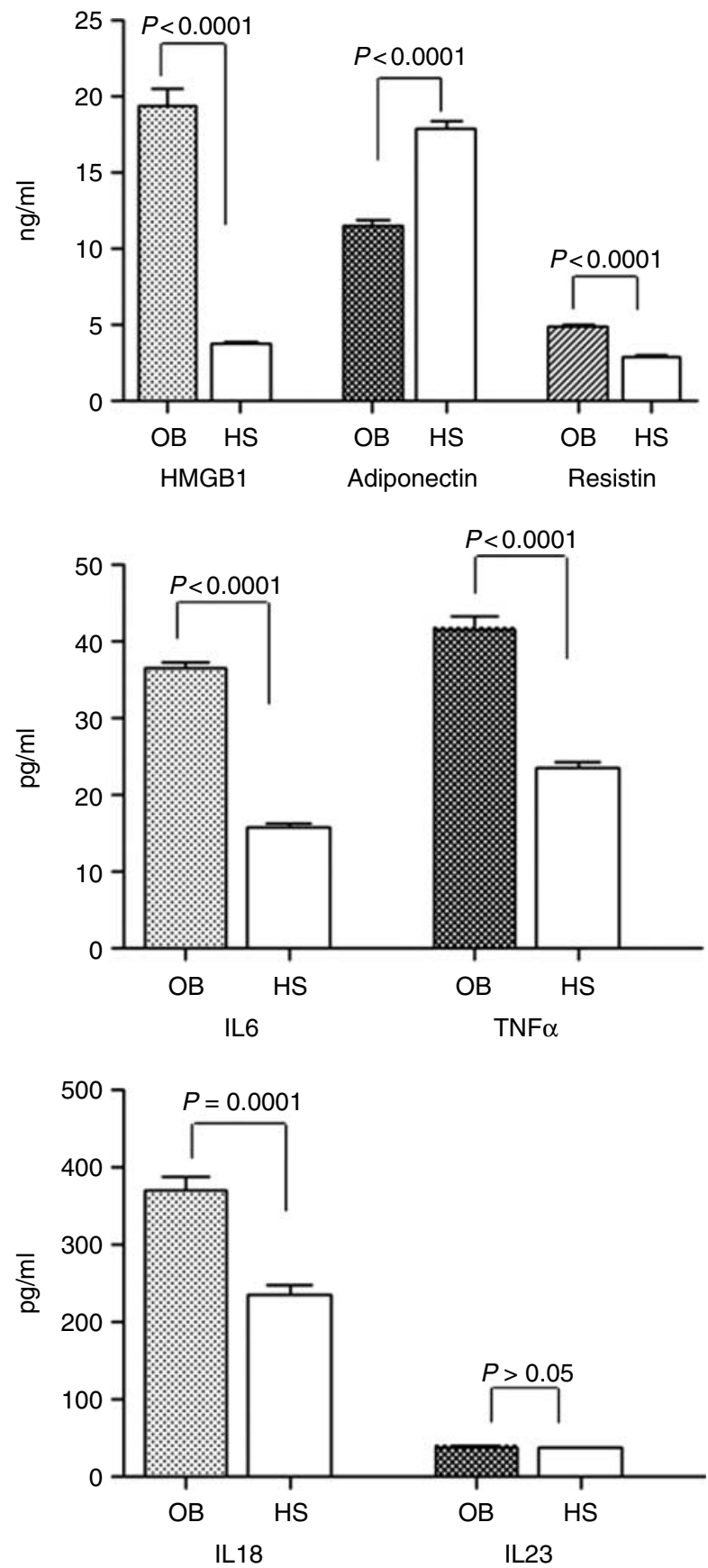

Figure $1 \mathrm{HMGB} 1$ and cytokine levels in obese patients and control groups. OB, obese children; HS, healthy subjects.
Obese patients were characterized by lower levels of adiponectin $(P<0.0001)$ when compared with normalweight children $(11.5 \pm 2.2$ vs $17.9 \pm 3.1 \mathrm{ng} / \mathrm{ml})$. There were no significant differences $(P=0.39)$ in IL23 levels between the two groups $(38.6 \pm 11.1$ vs $36.9 \pm 10.3 \mathrm{pg} / \mathrm{ml}$ ) (Fig. 1),

\section{Univariate correlations and multiple regression of HMGB1}

Correlations between HMGB1 values and clinical parameters were analyzed in all obese patients. HMGB1 was found to be directly correlated with BMI $(r=0.65 ; P<0.0001)$, IL23 $(r=0.30 ; P=0.02)$, IL6 $(r=0.53 ; P<0.0001)$, CRP $(r=0.44 ; P=0.001)$, $\mathrm{FT}_{3}(-0.31 ; P=0.008)$, HDL $(r=0.52 ; P=0.0001)$, and HOMA-IR $(r=0.42 ; P=0.0008)$, whereas an inverse correlation was found with diastolic blood pressure (DBP) values $(r=-0.30 ; P=0.01)$. The variables found to be significantly correlated at univariate analysis were introduced in a multivariate model using HMGB1 as a dependent variable. Significance was only maintained for the correlation between HMGB1 and BMI, IL23, IL6, FT 3 , HDL, and HOMA-IR (Fig. 2). By contrast, the correlations with CRP and diastolic blood pressure values found at univariate analysis were lost. The obtained data are summarized in Table 2.

\section{Characteristics of HMGB1 as diagnostic marker of MS in obese children}

ROC analyses were performed in order to define the diagnostic profile of HMGB1, IL6, and adiponectin in identifying the MS among obese children. The area under the ROC curve for HMGB1 was 0.992. When the cutoff values of HMGB1 were set at $18.6 \mathrm{ng} / \mathrm{ml}$, sensitivity and specificity of the marker used for the diagnosis were 94.7 and $97.5 \%$ respectively.

ROC analysis showed an AUC for IL6 of 0.74 with a best cutoff level of $36.9 \mathrm{ng} / \mathrm{ml}$ (sensitivity $73.7 \%$ and specificity $78 \%$ ), while the AUC for adiponectin was 0.72 with a best cutoff level of $10.9 \mathrm{mg} / \mathrm{dl}$ (sensitivity $68.4 \%$ and specificity $75.6 \%$ ).

HMGB1 area was statistically different compared with that of IL6 and adiponectin $(P=0.002$ and $P<0.001$ respectively). On the contrary, the difference between the IL6 and adiponectin areas was not significant ( $P=0.75$; Fig. 3$)$.

\section{Discussion}

This study demonstrated that childhood obesity is characterized by a chronic low-grade inflammation process, detected through a panel of inflammatory markers. In particular, we underlined the role of HMGB1, which was extremely high in obese children and strictly connected with other cytokines, such as IL6, 

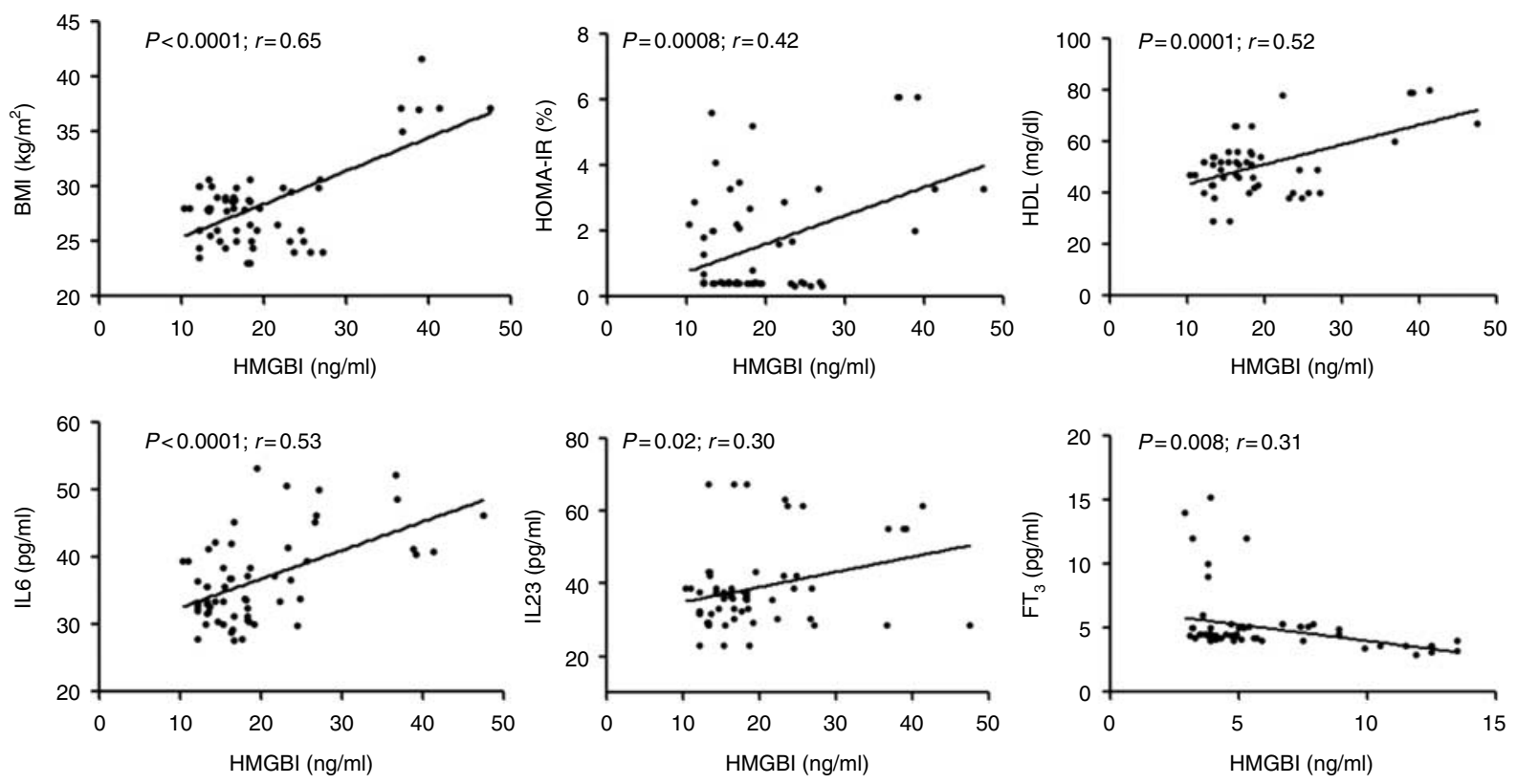

Figure 2 Univariate correlations of HMGB1. Number of obese patients: 60 .

TNF $\alpha$, IL18, resistin, and adiponectin. The direct correlation observed between HMGB1 and BMI is evidence of the link between obesity and inflammation.

Several studies have highlighted the strong relationship between obesity, BMI, and inflammation $(26,27)$. Garanty-Bogacka et al. (28) revealed that, after a program of physical activity and low-calorie diet, there was a reduction in the levels of inflammatory cytokines associated with a consequential improvement in obesity markers, such as BMI. Furthermore, we demonstrated a direct correlation between HMGB1, CRP, and IL6.

The liver is known to be a major source of CRP, but its secretion is strongly dependent on IL6 levels (29). This could be a physiopathological explanation for the loss of correlation, after multivariate analysis, between HMGB1 and CRP. The results concerning the independent correlation between IL6 and HMGB1 are a further confirmation that HMGB1 plays a key role in the inflammatory process characterizing the obese child.

In addition, Scaffidi et al. (30) and O'Connor et al. (31) have shown that, during the inflammatory process, HMGB1 is released by monocytes and macrophages actively and passively from necrotic cells, inducing the production of inflammatory cytokines, such as IL6.

We also found, after multivariate analysis, an inverse correlation between HMBG1 and $\mathrm{FT}_{3}$ levels. Elevated TSH concentrations in association with normal or slightly elevated $\mathrm{FT}_{4}$ and/or $\mathrm{FT}_{3}$ levels have been consistently found in obese subjects (32), but the mechanisms underlying these thyroid hormonal changes are still unclear. Whether higher TSH in childhood obesity is adaptive, or an increasing metabolic rate is an attempt to reduce further weight gain, or indicates subclinical hypothyroidism or resistance, remains controversial (33). D'Adamo et al. (34) demonstrated that an increased oxidative stress might represent one of the key regulators of thyroid hormones levels. HMGB1 may be a marker of thyroid dysfunction, probably due to the chronic inflammatory process associated with obesity. While we did not find a statistically significant difference of IL23 levels between obese children and the control group, we have noted, however, a direct and strict correlation between IL23 and HMGB1.

IL23 is a cytokine that regulates the chronic inflammation and plays a key role during bacterial infections, regulating $\mathrm{T}$ lymphocyte actions (35). Similarly, HMGB1 has been shown to have a key role

Table 2 Univariate and multiple regression analysis of HMBG1 in obese children.

\begin{tabular}{lccc}
\hline Variable & Partial $\mathbf{R}$ & $\boldsymbol{\beta}$ & $\boldsymbol{P}$ value \\
\hline BMI & $0.62(P<0.0001)$ & 0.60 & 0.003 \\
FT $_{3}$ & $-0.31(P=0.008)$ & -0.32 & 0.0004 \\
HDL & $0.40(P=0.0004)$ & 0.39 & $<0.0001$ \\
IL23 & $0.33(P=0.001)$ & 0.61 & 0.02 \\
IL6 & $0.30(P=0.003)$ & 0.32 & 0.02 \\
Diastolic BP & $-0.34(P=0.001)$ & -0.26 & $>0.05$ \\
CRP & $0.50(P<0.0001)$ & 0.09 & $>0.05$ \\
HOMA-IR & $0.48(P<0.0001)$ & 0.47 & $<0.0001$
\end{tabular}

Dependent variable: HMBG1; $\beta$ : standardized coefficient of correlation. BP, blood pressure; HOMA-IR, homeostasis model assessment of insulin resistance; IL, interleukin; CRP, C-reactive protein; HMGB1, high-mobility group protein B1. 


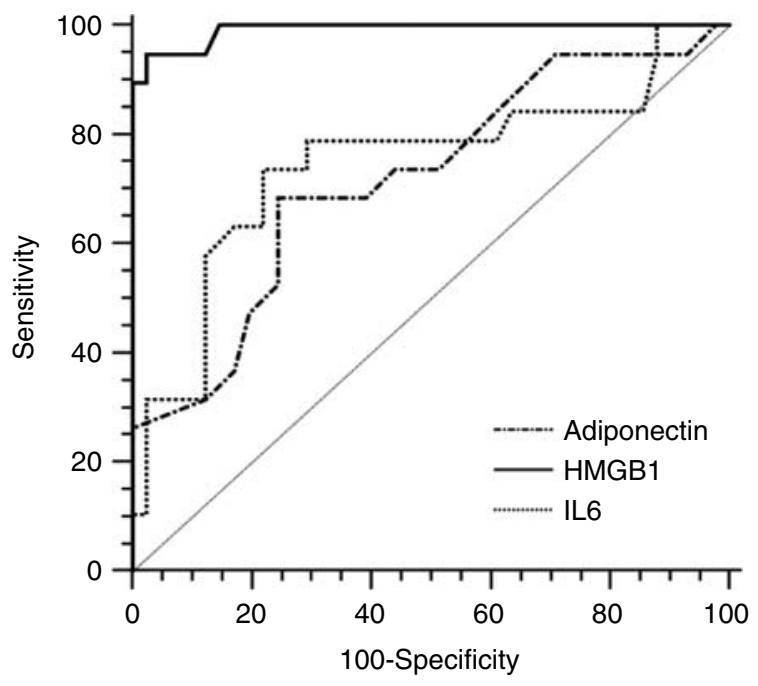

Figure 3 ROC curve analysis.

in different infectious diseases. Wang has in fact demonstrated that HMGB1 is a late mediator in animal models of sepsis (36), able to promote the bacterial products identification by immune system cells mediating the beginning of the immune reaction (37). Moreover, anti-HMGB1 antibodies have been demonstrated to confer protection in animal models of sepsis and endotoxemia (38). Recently, Liu et al. (39) demonstrated that IL23 is strongly dependent on HMGB1, which is able to induce IL23 synthesis through the pathway of TLR4. To our knowledge, these are the first data evaluating the roles of HMGB1 in childhood obesity, demonstrating that it may be also an important diagnostic marker for MS.

MS is a cluster of cardiovascular disease risk factors that include glucose intolerance, hypertension, elevated TG, low HDL-cholesterol, and obesity, characterized by low prevalence (40). The analysis of our data revealed a close correlation between HMGB1 and all parameters included in the diagnostic criteria of MS.

As shown by ROC curves, HMGB1 is an excellent diagnostic marker for this condition. In fact, we have demonstrated that HMGB1, when compared with adiponectin and IL6, had the highest sensitivity and specificity to identify MS among obese children.

This study has some limitations that should be mentioned. It was a single-center study, and the cohort of patients was relatively small. A larger study population could further reduce this bias and make the results more reliable. At the same time, the lack of adult confounding factors (smoking, advanced vascular disease, chronic conditions, etc.) in our young participants confers a certain advantage in clarifying the interrelationships found. In fact, HMGB1, as a critical mediator of inflammation, could be altered by acute infectious processes.
Additional research should determine whether inflammation incites a cascade that over many years leads to cardiovascular damage and subsequent cardiovascular events and whether earlier exposure to inflammation causes cumulative damage. Knowledge about early markers, such as HMGB1, may facilitate to refine prevention strategies and to provide a useful tool for the diagnosis and treatment of childhood obesity and its complications, such as MS.

\section{Declaration of interest}

The authors declare that there is no conflict of interest that could be perceived as prejudicing the impartiality of the research reported.

\section{Funding}

This research did not receive any specific grant from any funding agency in the public, commercial or not-for-profit sector.

\section{Author contribution statement}

Dr T Arrigo carried out the initial analyses, reviewed and revised the manuscript, and approved the final manuscript as submitted. Dr V Chirico conceptualized and designed the study, drafted the initial manuscript, and approved the final manuscript as submitted. V Salpietro carried out the initial analyses, reviewed and revised the manuscript, and approved the final manuscript as submitted. Dr C Munafò designed the data collection instruments, coordinated and supervised data collection, critically reviewed the manuscript, and approved the final manuscript as submitted. Dr V Ferraù carried out the initial analyses, reviewed and revised the manuscript, and approved the final manuscript as submitted. Dr E Gitto carried out the initial analyses, reviewed and revised the manuscript, and approved the final manuscript as submitted. Dr A Lacquaniti conceptualized and designed the study, drafted the initial manuscript, and approved the final manuscript as submitted. Dr C Salpietro designed the data collection instruments, coordinated and supervised data collection, critically reviewed the manuscript, and approved the final manuscript as submitted.

\section{References}

1 Kurtoglu S, Akin L, Kendirci M, Hatipoglu N, Elmali F \& Mazicioglu M. The absence of insulin resistance in metabolic syndrome definition leads to underdiagnosing of metabolic risk in obese patients. European Journal of Pediatrics 2012171 1331-1337. (doi:10.1007/s00431-012-1724-6)

2 Calcaterra V, Klersy C, Muratori T, Telli S, Caramagna C, Scaglia F, Cisternino M \& Larizza D. Prevalence of metabolic syndrome (MS) in children and adolescents with varying degrees of obesity. Clinical Endocrinology 200868 868-872. (doi:10.1111/j.13652265.2007.03115.x)

3 Ciprandi G, Caimmi D, Raschetti R, Miraglia Del Giudice M, Salpietro C, Caimmi S \& Castellazzi AM. Adipokines and their role in allergies. International Journal of Immunopathology and Pharmacology 201124 13-16.

4 Schipper HS, Nuboer R, Prop S, van den Ham HJ, de Boer FK, Kesmir C, Mombers IM, van Bekkum KA, Woudstra J, Kieft JH et al. Systemic inflammation in childhood obesity: circulating inflammatory mediators and activated $\mathrm{CD} 14(++)$ monocytes. Diabetologia 201255 2800-2810. (doi:10.1007/s00125-0122641-y) 
5 Jeffery AN, Murphy MJ, Metcalf BS, Hosking J, Voss LD, English P, Sattar N \& Wilkin TJ. Adiponectin in childhood. International Journal of Pediatric Obesity 20083 130-140. (doi:10.1080/ 17477160801954538 )

6 Greenberg AS \& McDaniel ML. Identifying the links between obesity, insulin resistance and $\beta$-cell function: potential role of adipocyte-derived cytokines in the pathogenesis of type 2 diabetes. European Journal of Clinical Investigation 200232 24-34. (doi:10.1046/j.1365-2362.32.s3.4.x)

7 Pervanidou P \& Chrousos GP. Metabolic consequences of stress during childhood and adolescence. Metabolism 201261 611-619. (doi:10.1016/j.metabol.2011.10.005)

8 Cizmecioglu FM, Etiler N, Ergen A, Gormus U, Keser A, Hekim N, Hamzaoglu O \& Hatun S. Association of adiponectin, resistin and high sensitive CRP level with the metabolic syndrome in childhood and adolescence. Experimental and Clinical Endocrinology \& Diabetes 2009117 622-627. (doi:10.1055/s-0028-1112151)

9 John BJ, Irukulla S, Abulafi AM, Kumar D \& Mendall MA. Systematic review: adipose tissue, obesity and gastrointestinal diseases. Alimentary Pharmacology \& Therapeutics 200623 1511-1523. (doi:10.1111/j.1365-2036.2006.02915.x)

10 Wilkins J, Gallimore JR, Moore EG \& Pepys MB. Rapid automated high sensitivity enzyme immunoassay of C-reactive protein. Clinical Chemistry $1998 \mathbf{4 4} 1358-1361$.

11 Bianchi ME \& Beltrame M. Upwardly mobile proteins. Workshop: the role of HMG proteins in chromatin structure, gene expression and neoplasia. EMBO Reports 20001 109-114. (doi:10.1093/ embo-reports/kvd030)

12 Andersson U, Wang H, Palmblad K, Aveberger AC, Bloom O, Erlandsson-Harris H, Janson A, Kokkola R, Zhang M, Yang H et al. High mobility group 1 protein (HMG-1) stimulates proinflammatory cytokine synthesis in human monocytes. Journal of Experimental Medicine 2000192 565-570. (doi:10.1084/jem. 192.4.565)

13 Park JS, Gamboni-Robertson F, He Q, Svetkauskaite D, Kim JY, Strassheim D, Sohn JW, Yamada S, Maruyama I, Banerjee A et al. High mobility group box 1 protein interacts with multiple Toll-like receptors. American Journal of Physiology. Cell Physiology 2006 290 C917-C924. (doi:10.1152/ajpcell.00401.2005)

14 Goldstein RS, Bruchfeld A, Yang L, Qureshi AR, GallowitschPuerta M, Patel NB, Huston BJ, Chavan S, Rosas-Ballina M, Gregersen PK et al. Cholinergic anti-inflammatory pathway activity and high mobility group box-1 (HMGB1) serum levels in patients with rheumatoid. Molecular Medicine 200713 210-215. (doi:10.2119/2006-00108.Goldstein)

15 Cole TJ, Bellizzi MC, Flegal KM \& Dietz WH. Establishing a standard definition for child overweight and obesity worldwide: international survey. BMJ 2000320 1-6. (doi:10.1136/bmj.320. $7244.1240)$

16 Tanner JM \& Whitehouse RH. Clinical longitudinal standards for height, weight, height velocity, weight velocity, and stages of puberty. Archives of Disease in Childhood 197651 170-179. (doi:10.1136/adc.51.3.170)

17 McCarthy HD, Jarrett KV \& Crawley HF. The development of waist circumference percentiles in British children aged 5.0-16.9 y. European Journal of Clinical Nutrition $2001 \quad 55$ 902-907. (doi:10.1038/sj.ejcn.1601240)

18 National High Blood Pressure Education Program Working Group on High Blood Pressure in Children and Adolescents. The fourth report on the diagnosis, evaluation, and treatment of high blood pressure in children and adolescents. Pediatrics 2004 114 555-576. (doi:10.1542/peds.114.2.S2.555)

19 Cole TJ, Freeman JV \& Preece MA. Body mass index reference curves for the UK, 1990. Archives of Disease in Childhood 199573 25-29. (doi:10.1136/adc.73.1.25)

20 Ten S \& Maclaren N. Insulin resistance syndrome in children. Journal of Clinical Endocrinology and Metabolism 200489 2526-2539. (doi:10.1210/jc.2004-0276)

21 Haffner FM, Gonzales C, Miettinem H, Kennedy E \& Stern MP. A prospective analysis of the HOMA model. Diabetes Care 199619 1138-1141. (doi:10.2337/diacare.19.10.1138)
22 Gungor N, Saad R, Janosky J \& Arslanian S. Validation of surrogate estimates of insulin sensitivity and insulin secretion in children and adolescents. Journal of Pediatrics $2004 \quad 144$ 47-55. (doi:10.1016/j.jpeds.2003.09.045)

23 Keskin M, Kurtoglu S, Kendirci M, Atabek ME \& Yazici C. Homeostasis model assessment is more reliable than the fasting glucose/insulin ratio and quantitative insulin sensitivity check index for assessing insulin resistance among obese children and adolescents. Pediatrics 2005115 e500-e503. (doi:10.1542/peds. 2004-1921)

24 Invitti C, Guzzaloni G, Gilardini L, Morabito F \& Viberti G. Prevalence and concomitants of glucose intolerance in European obese children and adolescents. Diabetes Care 200326 118-124. (doi:10.2337/diacare.26.1.118)

25 Weiss R, Dziura J, Burgert TS, Tamborlane WV, Taksali SE, Yeckel CW, Allen K, Lopes M, Savoye M, Morrison J et al. Obesity and the metabolic syndrome in children and adolescents. New England Journal of Medicine $2004 \quad 350 \quad 2362-2374$. (doi:10.1056/NEJMoa031049)

26 Siervo M, Ruggiero D, Sorice R, Nutile T, Aversano M, Iafusco M, Vetrano F, Wells JC, Stephan BC \& Ciullo M. Body mass index is directly associated with biomarkers of angiogenesis and inflammation in children and adolescents. Nutrition 201228 262-266. (doi:10.1016/j.nut.2011.06.007)

27 Dedoussis GV, Kapiri A, Samara A, Dimitriadis D, Lambert D, Pfister M, Siest G \& Visvikis-Siest S. Expression of inflammatory molecules and associations with BMI in children. European Journal of Clinical Investigation 201040 388-392. (doi:10.1111/ j.1365-2362.2010.02277.x)

28 Garanty-Bogacka B, Syrenicz M, Goral J, Krupa B, Syrenicz J, Walczak M \& Syrenicz A. Changes in inflammatory biomarkers after successful lifestyle intervention in obese children. Endokrynologia Polska 201162 499-505.

29 Park H, Jung Yul Park J \& Yuc R. Relationship of obesity and visceral adiposity with serum concentrations of CRP, TNF-a and IL-6. Diabetes Research and Clinical Practice 200569 29-35. (doi:10.1016/j.diabres.2004.11.007)

30 Scaffidi P, Misteli T \& Bianchi ME. Release of chromatin protein HMGB1 by necrotic cell triggers inflammation. Nature $2002 \mathbf{4 1 8}$ 191-195. (doi:10.1038/nature00858)

31 O'Connor KA, Hansen MK, Rachal Pugh C, Deak MM, Biedenkapp JC, Milligan ED, Johnson JD, Wang H, Maier SF, Tracey KJ et al. Further characterization of high mobility group box 1 (HMGB1) as a proinflammatory cytokine: central nervous system effects. Cytokine 200324 254-265. (doi:10.1016/j.cyto. 2003.08.001)

32 Brufani C, Manco M, Nobili V, Fintini D, Barbetti F \& Cappa M. Thyroid function tests in obese prepubertal children: correlations with insulin sensitivity and body fat distribution. Hormone Research in Paediatrics $2012 \mathbf{7 8}$ 100-105. (doi:10.1159/ 000341363)

33 Pacifico L, Anania C, Ferraro F, Andreoli GM \& Chiesa C. Thyroid function in childhood obesity and metabolic comorbidity. Clinica Chimica Acta 2012413 396-405. (doi:10.1016/j.cca.2011.11.013)

34 D'Adamo E, De Leonibus C, Giannini C, Corazzini V, De Remigis A, Chiarelli F \& Mohn A. Thyroid dysfunction in obese pre-pubertal children: oxidative stress as a potential pathogenetic mechanism. Free Radical Research 201246 303-309. (doi:10.3109/ 10715762.2011.653967)

35 Gong W, Li Y, Chao F, Huang G \& He F. Amino acid residues 201-205 in C-terminal acidic tail region plays a crucial role in antibacterial activity of HMGB1. Journal of Biomedical Science 200916 83. (doi:10.1186/1423-0127-16-83)

36 Wang H, Zhu S, Zhou R, Li W \& Sama AE. Therapeutic potential of HMGB1-targeting agents in sepsis. Expert Reviews in Molecular Medicine 200810 e32. (doi:10.1017/S1462399408000884)

37 Youn JH, Oh YJ, Kim ES, Choi JE \& Shin JS. High mobility group box 1 protein binding to lipopolysaccharide facilitates transfer of lipopolysaccharide to CD14 and enhances lipopolysaccharidemediated TNF- $\alpha$ production in human monocytes. Journal of Immunology 2008180 5067-5074. 
38 Yang H, Ochani M, Li J, Qiang X, Tanovic M, Harris HE, Susarla SM, Ulloa L, Wang H, DiRaimo $\mathrm{R}$ et al. Reversing established sepsis with antagonists of endogenous high-mobility group box 1. PNAS 2004101 296-301. (doi:10.1073/pnas. 2434651100)

39 Liu Y, Yuan Y, Li Y, Zhang J, Xiao G, Vodovotz Y, Billiar TR, Wilson MA \& Fan J. Interacting neuroendocrine and innate and acquired immune pathways regulate neutrophil mobilization from bone marrow following hemorrhagic shock. Journal of Immunology $2009182572-580$.
40 Papoutsakis C, Yannakoulia M, Ntalla I \& Dedoussis GV. Metabolic syndrome in a Mediterranean pediatric cohort: prevalence using International Diabetes Federation-derived criteria and associations with adiponectin and leptin. Metabolism 201261 140-145. (doi:10.1016/j.metabol.2011.06.006)

Received 25 October 2012

Revised version received 22 January 2013

Accepted 4 February 2013 